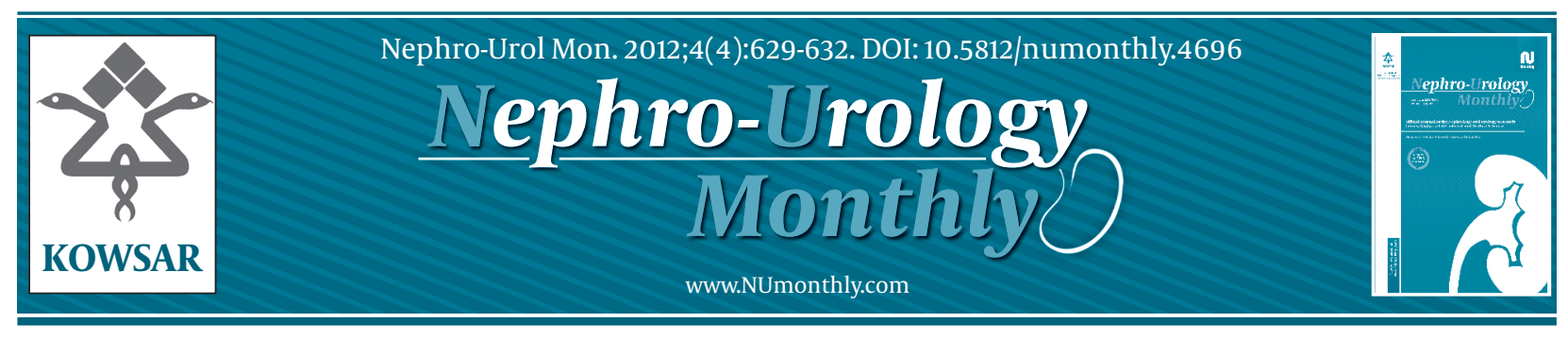

\title{
Comparison of Before and After Varicocelectomy Levels of Nitric Oxide in Seminal Fluid of Infertile Men
}

\author{
Hossein Keyhan ${ }^{1 *}$, Alireza Dadvar ${ }^{1}$, Mohammad Ansari $^{2}$, Kheirollah Rafiee ${ }^{2}$ \\ ${ }^{1}$ Urology Unit, Boali Hospital, Islamic Azad University Tehran Medical Branch, Tehran, IR Iran \\ 2 Department of Biochemistry, Tehran University of Medical Sciences, Tehran, IR Iran
}

A R T I C L E I N F O

Article type:

Original Article

Article history:

Received: 01 Mar 2012

Revised: 15 Mar 2012

Accepted: 05 Apr 2012

Keywords:

Varicocele

Nitric Oxide

Infertility

Semen

\begin{abstract}
A B S T R A C T
Background: Since nitric oxide (NO) has an oxidant activity, lower levels following a varicocelectomy may result in better functioning sperm, improved semen quality and consequently higher fertility rates. However, this procedure should be examined in more detail.

Objectives: Accordingly, this study was performed to compare the before and after varicocelectomy levels of NO in the seminal fluid of infertile men.

Patients and Methods: In this before and after comparative study, 20 consecutive patients attending a training hospital in Tehran, Iran were recruited. All of these men had primary or secondary infertility accompanied with a varicocele. A semen sample was collected from the men in two phases, first before their varicocelectomy and two months after their operation.

Results: NO levels differed significantly across the study and the mean ( \pm standard deviation) levels of NO in the patients were $30.59 \pm 10.35 \mu \mathrm{M} / \mathrm{L}$ and $21.48 \pm 32.14 \mu \mathrm{M} / \mathrm{L}$ in the before and after phases of the study, respectively $(P=0.009)$.

Conclusions: According to the results obtained in this study, it may be concluded that in future, levels of NO should be taken into consideration together with other parameters for the evaluation of patients who are affected by varicoceles, to determine probable therapeutic responses.

Published by Kowsar Corp, 2012. cc 3.0.
\end{abstract}

Implication for health policy/practice/research/medical education:

The present study has compared the before and after varicocelectomy levels of NO in the seminal flouid of infertile men and it can be useful for urologists.

- Please cite this paper as:

Keyhan H, Dadvar A, Ansari M, Rafiee K. Comparison of Before and After Varicocelectomy Levels of Nitric Oxide in Seminal Fluid of Infertile Men. Nephro-Urol Mon.2012;4(4): 629-32. DOI:10.5812/numonthly.4696

\section{Background}

A varicocele is a dilatation of the pampiniform venous plexus and the internal spermatic vein (1). Varicoceles are a well-recognized cause of decreased testicular function and they occur in approximately $15-20 \%$ of all males and in $40 \%$ of infertile males $(2,3)$. Varicoceles are the most common cause of poor sperm production and decreased semen quality (4). Varicoceles are easy to identify and to surgically correct $(5,6)$.

Reasons for surgical correction of a diagnosed varicocele include; relieving significant testicular discomfort or pain not responsive to routine symptomatic treatment, reducing testicular atrophy, and addressing the

\footnotetext{
* Corresponding author: Hossein Keyhan, Urology Unit, Boali Hospital, Islamic Azad University Tehran Medical Branch, Tehran, IR Iran. Tel: +98-9123110306, Fax: +98-2122951133, E-mail: hosseinkeyhan@gmail.com
}

DOI:10.5812/numonthly.4696

(C) 2012 Nephrology and Urology Research Center and Baqiyatallah University of Medical Sciences; Published by Kowsar Corp.

This is an Open Access article distributed under the terms of the Creative Commons Attribution License (http://creativecommons.org/licenses/by/3.0), which permits unrestricted use, distribution, and reproduction in any medium, provided the original work is properly cited. 
possible contribution to unexplained male infertility (7, 8). A varicocele may cause progressive damage to the testes, resulting in further atrophy and impairment of seminal parameters $(2,3)$.

A scrotal varicocele is the most correctable factor in a male with poor semen quality (4); therefore, varicocele repair should be considered a viable choice for appropriately selected individuals and couples with otherwise unexplained infertility. Varicocele repair has been shown to improve semen parameters in most men and creates possible improvements in fertility, in addition, the risks of varicocele repair are small (9-11). However, it is not clear what the leading cause of the therapeutic response in men with varicocele consists of, but it has been reported that nitric oxide levels in the seminal fluid are significantly different in men with a varicocele compared to those without this condition $(12,13)$.

Recent studies have shown that nitric oxide (NO) levels increase in the spermatic veins and seminal plasma of patients with varicoceles. Some observations have indicated that NO may modulate sperm function. Low concentrations of exogenous NO donors have been shown to enhance; human sperm motility, viability, capacitation, and binding to the zona pellucida (14-16). Conversely, at higher concentrations, they decrease human sperm motility and induce sperm toxicity $(17,18)$.

\section{Objectives}

Since nitric oxide has oxidization ability (19), this may decrease after a varicocelectomy resulting in better functioning of sperm and semen quality, with consequently higher fertility rates. However, this phenomenon should be examined in greater detail. Accordingly, this study was performed to compare the before and after varicocelectomy levels of nitric oxide in the seminal fluid of infertile men.

\section{Patients and Methods}

In this before and after comparative study, 20 consecu- tive patients attending a training hospital in Tehran, Iran were recruited. All of the men had primary or secondary infertility accompanied by varicoceles. The exclusion criteria were; history of nitrate drug use, active infection (especially urinary tract infection), and penile deformities leading to difficult insertion.

The semen samples were collected from the patients in two phases, first before the varicocelectomy and two months after the operation. The study was accepted by the Ethical Committee Board of the Tehran Branch of Azad University of Medical Sciences and was in accordance with good clinical practice and the Declaration of Helsinki. The study variables included; age, grade of varicocele, sperm count, normal morphology percentage, motility percentage, and level of NO in the seminal fluid.

Semen specimens were collected in sterile containers 48 to 72 hours after sexual abstinence. Specimens were allowed to thaw at room temperature for approximately 30 minutes, and a conventional semen examination was carried out under sterile conditions within one hour after collection. A part of the sample was stored at $-20^{\circ} \mathrm{C}$ for a NO assay.

\subsection{NO Assay}

The thawed semen was centrifuged at $1000 \mathrm{~g}$ for five minutes to remove the sperm cells. Then $50 \mu \mathrm{L}$ of saturated zinc sulphate was added to $500 \mu \mathrm{L}$ of each sample and left for 25-30 minutes at room temperature to precipitate the proteins. Thereafter, the samples were re-centrifuged with $13000 \mathrm{~g}$ the supernatant which was collected for a nitrite assay (as an index of NO production) by the Griess method. In brief, one hundred $\mu \mathrm{L}$ of each sample were transferred to a 96-well microtiter plate and $100 \mu \mathrm{L}$ of Griess reagent (2\% sulfanilamide in $5 \% \mathrm{HCl}$ solution and $0.1 \% \mathrm{~N}$-(1-Naphtyl) ethylendiamine in water) was added. In addition, to reduce nitrate to nitrite, $100 \mu \mathrm{L}$ vanadium chloride III $0.8 \%$ was added to each sample and they were left in an incubator at $37^{\circ} \mathrm{C}$ for one hour. The samples were then evaluated using a spectrophotometer method by an ELISA-reader (ANTHOS 2020, Anthos 2020 UK, Bio-

\begin{tabular}{llll}
\hline Table 1. Spermogram Findings in Before and After Phases ${ }^{\text {a }}$ & Mean & Standard Deviation \\
\hline & Phase & & 31.22380 \\
\hline Count $\left(\mathbf{x 1 0}^{\mathbf{6}}\right.$ ) & Before & 31.0692 & 50.78838 \\
& After & 31.8778 & 18.010 \\
\hline Motility (\%) & Before & 40.77 & 20.775 \\
& After & 48.78 & 18.085 \\
\hline Morphology (NL \%) & Before & 62.31 & 20.324 \\
\hline
\end{tabular}

\footnotetext{
${ }^{\mathrm{a}}$ There was no significant difference in any of the factors $(P>0.05)$.
} 
chrom Ltd.) in $540 \mathrm{~nm}$. Samples were run in triplicate to decrease the possibility of laboratory errors and finally the mean amounts were calculated. All chemicals and reagents were purchased from Merck, Germany.

The statistical analysis was performed using SPSS version 18.0 software (SPSS Inc, Chicago, IL, USA) using a Student's t-test and Chi-square tests. A $P$ value of 0.05 was considered significant.

\section{Results}

The mean ( \pm standard deviation) age of the patients was $27.15 \pm 4.79$ years, ranging from 23 to 40 years. The varicocele grade was I in one patient (5\%), II in 14 (70\%), and III in five subjects (25\%). There was no significant difference between sperm count, normal morphology percentage, and motility percentage among the patients in the before and after phases (Table 1), $(P>0.05)$.

NO levels differed significantly across the study and the mean ( \pm standard deviation) levels of NO in the patients were $30.59 \pm 10.35 \mu \mathrm{M} / \mathrm{L}$ and $21.48 \pm 32.14 \mu \mathrm{M} / \mathrm{L}$ in the before and after phases of the study, respectively $(P=0.009)$. The age of the patients and the grade of the patients' varicocele were not related to decreases in NO levels $(P>0.05)$. There was a significant linear association between an increase in sperm count, normal morphology percentage, and motility percentage with the amount of NO decrease $(P<0.05)$.

\section{Discussion}

NO production and consequently increased reactive oxygen free radicals may influence sperm production, motility and morphology in patients with varicoceles and result in poor fertility function (20-22). This situation is useful in explaining the pathogenesis of both testis and sperm dysfunction in varicoceles, especially since our study showed a noteworthy difference between NO levels in the before and after phases of this study and this decrease was significantly related to improved semen quality parameters.

Mitropoulos et al., (14) assessed peripheral blood samples in subfertile male subjects with varicoceles and compared them with blood samples from the dilated varicocele vein before ligation. The authors found elevated oxidative stress due to the release of nitric oxide synthase and xanthine oxidase within the dilated spermatic vein. This result was also observed in our study in the beforevaricocelectomy phase.

In a similar study by Ozbek et al. (23) in Turkey, it was observed that preoperative and postoperative mean seminal fluid NO levels in patients with varicoceles were 114.82 $+/-33.02 \mu \mathrm{M} / \mathrm{L}$ and $93.17+/-27.24 \mu \mathrm{M} / \mathrm{L}$, respectively showing a statistically significant difference between mean preoperative and postoperative seminal NO levels, this was similar to our study results.

Mostafa et al. (24) in Egypt found a statistically signifi- cant reduction in the three-month postoperative levels of NO compared with the pre-operative values in men who underwent a varicocelectomy, and this difference was observed even after one month. According to a study performed by Sakamoto et al. (25), there was a significant increase in sperm concentrations and reduction in $\mathrm{NO}$ levels following a varicocelectomy, this change was also observed in our study, but only for NO levels.

According to the results obtained in this study, it may be concluded that NO levels should be taken into consideration in the future, together with other parameters for the evaluation of patients who are affected by varicoceles to determine the probable therapeutic response. It may also be said, that patients with higher preoperative NO levels are possibly better candidates for a varicocelectomy and drug therapy, which will decrease NO levels in the seminal fluid and this may lead to better sperm quality.

However, further studies should be carried out to obtain more definite results, especially in larger sample populations. Observing patients' seminal parameters (sperm count, motility and normal morphology) six months following a varicocelectomy to determine the best response to a varicocelectomy should also be included.

\section{Acknowledgments}

None declared.

\section{Authors' Contribution}

None declared.

\section{Financial Disclosure}

None declared.

\section{Funding/Support}

None declared.

\section{References}

1. Witt MA, Lipshultz LI. Varicocele: a progressive or static lesion? Urology. 1993;42(5):541-3.

2. Gorelick JI, Goldstein M. Loss of fertility in men with varicocele. Fertil Steril.1993;59(3):613-6.

3. Lund L, Larsen SB. A follow-up study of semen quality and fertility in men with varicocele testis and in control subjects. BrJUrol. 1998;82(5):682-6.

4. Marmar JL. The pathophysiology of varicoceles in the light of current molecular and genetic information. Hum Reprod Update. 2001;7(5):461-72.

5. Tilki D, Kilic E, Tauber R, Pfeiffer D, Stief CG, Ergun S. The complex structure of the smooth muscle layer of spermatic veins and its potential role in the development of varicocele testis. Eur Urol. 2007;51(5):1402-9; discussion 10.

6. Gat Y, Gornish M, Navon U, Chakraborty J, Bachar GN, Ben-Shlomo I. Right varicocele and hypoxia, crucial factors in male infertility: fluid mechanics analysis of the impaired testicular drainage system. Reprod Biomed Online. 2006;13(4):510-5.

7. Naughton CK, Nangia AK, Agarwal A. Pathophysiology of varicoceles in male infertility. Hum Reprod Update. 2001;7(5):473-81.

8. Joshi NV, Medina H, Osuna JA. Ultrastructural pathology of varicocele spermatozoa by using atomic force microscopy (AFM). 
Arch Androl. 2001;47(2):143-52

9. Said TM, Agarwal A, Sharma RK, Thomas AJ, Jr., Sikka SC. Impact of sperm morphology on DNA damage caused by oxidative stress induced by beta-nicotinamide adenine dinucleotide phosphate. Fertil Steril. 2005;83(1):95-103.

10. Agarwal A, Ikemoto I, Loughlin KR. Relationship of sperm parameters with levels of reactive oxygen species in semen specimens. J Urol. 1994;152(1):107-10.

11. de Lamirande E, Gagnon C. Reactive oxygen species and human spermatozoa. II. Depletion of adenosine triphosphate plays an important role in the inhibition of sperm motility. J Androl. 1992;13(5):379-86.

12. Sharma RK, Agarwal A. Role of reactive oxygen species in male infertility. Urology. 1996;48(6):835-50.

13. de Lamirande E, Gagnon C. Impact of reactive oxygen species on spermatozoa: a balancing act between beneficial and detrimental effects. Hum Reprod. 1995;10 (Suppl 1):15-21.

14. Mitropoulos D, Deliconstantinos G, Zervas A, Villiotou V, Dimopoulos C, Stavrides J. Nitric oxide synthase and xanthine oxidase activities in the spermatic vein of patients with varicocele: a potential role for nitric oxide and peroxynitrite in sperm dysfunction. J Urol.1996;156(6):1952-8.

15. Smith R, Kaune H, Parodi D, Madariaga M, Rios R, Morales I, et al. Increased sperm DNA damage in patients with varicocele: relationship with seminal oxidative stress. Hum Reprod. 2006;21(4):986-93.

16. Agarwal A, Prabakaran S, Allamaneni SS. Relationship between oxidative stress, varicocele and infertility: a meta-analysis. Reprod Biomed Online. 2006;12(5):630-3.

17. Allamaneni SS, Naughton CK, Sharma RK, Thomas AJ, Jr., Agarwal
A. Increased seminal reactive oxygen species levels in patients with varicoceles correlate with varicocele grade but not with testis size. Fertil Steril. 2004;82(6):1684-6.

18. Koksal IT, Tefekli A, Usta M, Erol H, Abbasoglu S, Kadioglu A. The role of reactive oxygen species in testicular dysfunction associated with varicocele. BJU Int. 2000;86(4):549-52.

19. Mehraban D, Ansari M, Keyhan H, Sedighi Gilani M, Naderi G, Esfehani F. Comparison of nitric oxide concentration in seminal fluid between infertile patients with and without varicocele and normal fertile men. Urol J.2005;2(2):106-10.

20. Kim ED, Leibman BB, Grinblat DM, Lipshultz LI. Varicocele repair improves semen parameters in azoospermic men with spermatogenic failure. J Urol.1999;162(3 Pt 1):737-40.

21. Daitch JA, Bedaiwy MA, Pasqualotto EB, Hendin BN, Hallak J, Falcone $\mathrm{T}$, et al. Varicocelectomy improves intrauterine insemination success rates in men with varicocele. JUrol. 2001;165(5):1510-

22. Santoro G, Romeo C, Impellizzeri P, Ientile R, Cutroneo G, Trimarchi F, et al. Nitric oxide synthase patterns in normal and varicocele testis in adolescents. BJU Int. 2001;88(9):967-73.

23. Ozbek E, Ilbey YY, Simsek A, Cekmen M, Balbay MD. Preoperative and postoperative seminal nitric oxide levels in patients with infertile varicocele. Arch Ital Urol Androl. 2009;81(4):248-50.

24. Mostafa T, Anis TH, El-Nashar A, Imam H, Othman IA. Varicocelectomy reduces reactive oxygen species levels and increases antioxidant activity of seminal plasma from infertile men with varicocele. Int J Androl. 2001;24(5):261-5.

25. Sakamoto Y, Ishikawa T, Kondo Y, Yamaguchi K, Fujisawa M. The assessment of oxidative stress in infertile patients with varicocele. BJU Int. 2008;101(12):1547-52. 